\title{
ADRIAN EVANS FESTSCHRIFT
}

\section{Carolyn Worth AM}

I know two things about Adrian Evans.

These do not include details of his stellar law career which others more knowledgeable can write about. The two things are firstly his development and support of the joint specialist legal

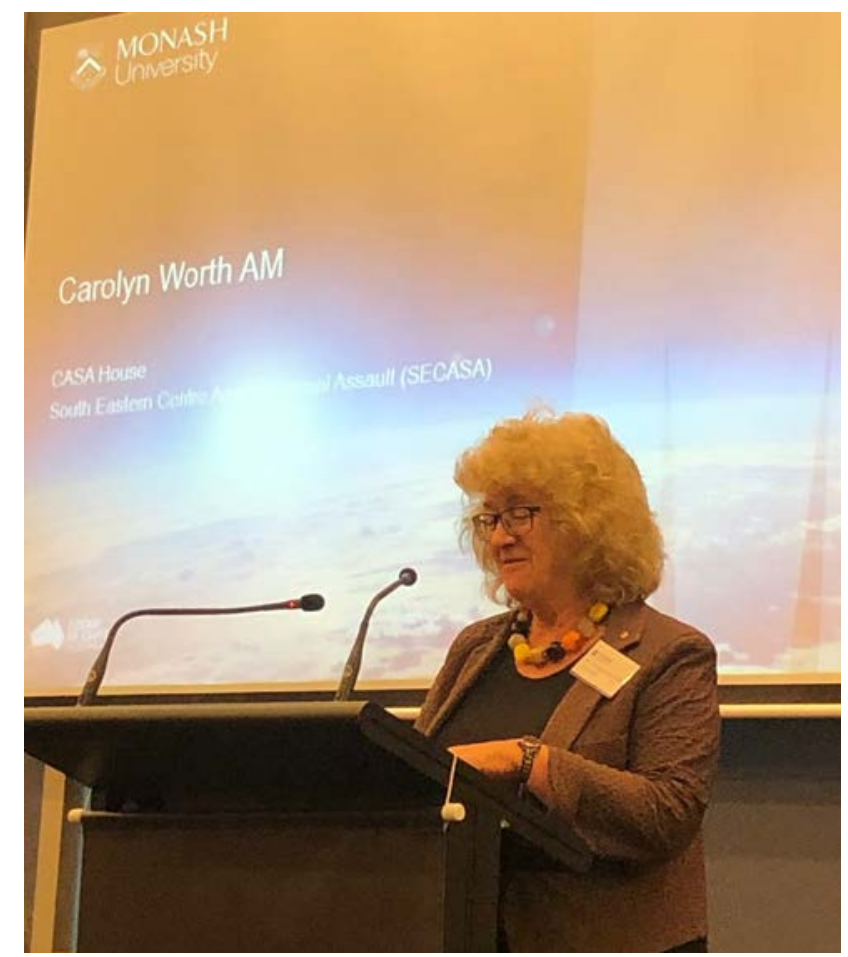
clinic that Springvale Monash Legal Service and the South Eastern Centre Against Sexual Assault (SECASA) started in 1992 which still operates and is an indication of his support for victim/survivors of sexual assault. The second thing I know is his enjoyment of bushwalking.

To start with the Joint Legal Clinic. In 1994 Adrian Evans had been overseas and returned inspired about specialist legal services amongst other things. He was very excited about clinics he had seen in operation in Canada on his study tour. He hoped that he could duplicate these clinics in Australia. He also wanted to "utilise the energies of the female students doing Law at Monash in a constructive manner." I on the other hand had a completely different agenda. I was looking for a better system for Victims of Crime applications than that provided at the time by private law firms. Those who recall those times will remember that there was very little money in preparing victims of crime applications so there was not a large amount of legal 
expertise in this area. I was concerned that a number of our clients had not received the service they deserved. An additional problem was that our more vulnerable clients were intimidated by the law offices we sent them to even those of the labour law firms. My final hope with creating the Clinic was to improve the attitude of SECASA counsellors to lawyers. Their main experience with lawyers, when I first started at SECASA, was predominantly of defence counsel who had either cross examined clients aggressively or the counsellors themselves.

After some minimal discussion Adrian and I established a 12 month pilot for a joint legal clinic that was to apply for compensation utilising the criminal injuries legislation under the Criminal Injuries Compensation Act (1972). SECASA was to provide the referrals and support clients to attend the clinic. Clients were to be interviewed with a counsellor present for support. It is worth mentioning that many of our clients are extremely vulnerable and have long histories of sexual assault starting in their childhood. Four female students were carefully selected for their perceived ability to deal with sexual assault victim/survivors. The clinic was launched by Jan Wade, the then Attorney General. 


\section{MonashHealth South Eastern CASA}

Joint Legal Clinic launch

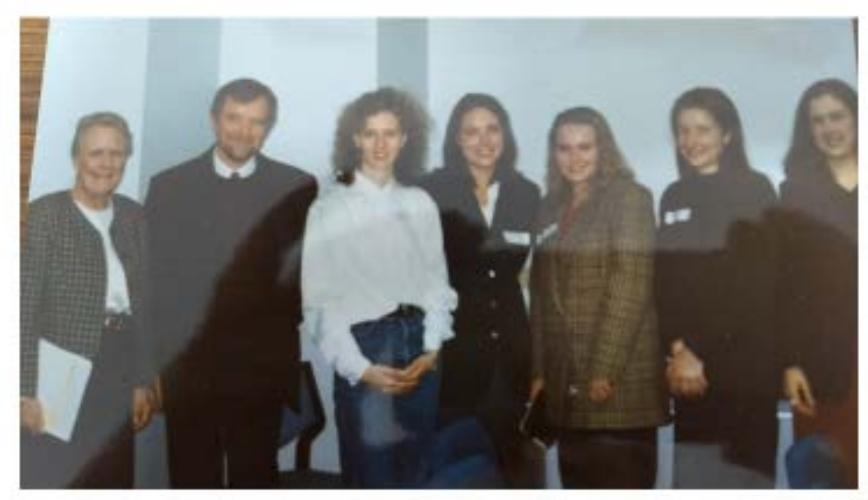

1995 was kinder time than now. The clinic was established with a handshake and a kiss and a hug. (There will be more about the hugs in a bit.) When the Clinic commenced we did not have a Memorandum of Understanding or an Agreement as we would need today. Lawyers from both sides had not spent hours working out the intricacies of who was responsible for what. Twenty years after the Clinic commenced Monash Health, who is SECASAS's auspicing body, were setting up a legal clinic in the hospital. They knew we had a Legal Clinic and asked if they could have a copy of the original documents for establishing the specialist legal clinic as a guide for their proposed clinic.. When there were told there was no original paperwork the bureaucrat who asked looked very puzzled and then said that it was fine if I did not want to give it to her. I said that they would have been welcome but that we had started the Joint Clinic on a trust basis. As I said kinder times.

The Joint Clinic has been in existence for 23 years. 


\section{MonashHealth}

\section{Supervisor Meghan Butterfield} at $20^{\text {th }}$ Birthday Party

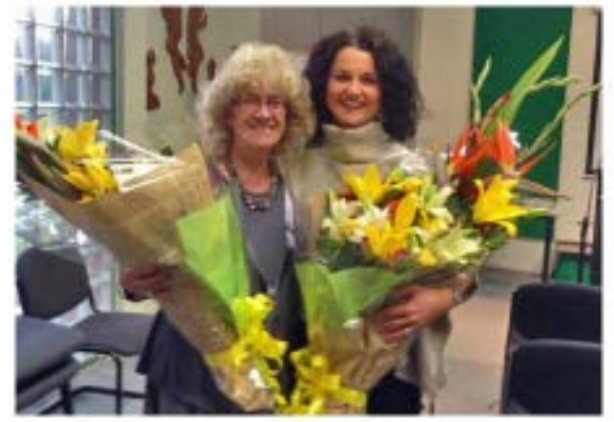

It is a tribute to Adrian's vision for innovative legal solutions and also his commitment

to victim/survivors of sexual assault. It has survived

- Legislative changes including Jeff Kennett's attempt to destroy VOCAT

- Difficult magistrates

- Aggressive clients

- Counsellor who appear unable to get reports in on time no matter what the penalty from me

The clinic has undergone many changes including

- becoming part of Advanced Professional Practice at Monash Law

- moving from SECASA's office to Springvale Monash Legal Service

- having male and female students

- paying the student supervisor 
The Clinic is, however, still true to Adrian's initial idea and provides our clients with a service that is not often duplicated in the private sector. The Clinic carries around 100 active files, has 3 groups of four final year law students doing Advanced Prof Prac and has 26 volunteer solicitors. Most of the volunteer solicitors are ex Monash students who did Advanced Prof Prac at the joint clinic.

A recent evaluation found that the clinic does better than the State average for awards which confirmed what I had always suspected and anecdotally knew.

Now to bushwalking and hugs. Not long after the clinic started Adrian mentioned that he liked bush walking. He said that with a number of friends he walked to the lighthouse at Wilson's Promontory annually. He suggested I might like to come on the next trip with Peter, my husband. It sounded like a terrific idea so we agreed. There was no mention at the time of the 1 in 2 gradient on the final part of the walk, which I have got used to over the years, or the undulating nature of the bush path on the way to the lighthouse. I enjoy the walk and the days at the Lighthouse recovering and preparing for the walk back. The years I miss because of other commitments I feel as though I have been deprived of a great treat.

However, I want to mention one particular year when there had been a large law conference in Melbourne. Adrian, who is very inclusive and enthusiastic, issued the invitation to a number of overseas presenters at the conference who were clearly esteemed lawyers, and men of a certain age, to come to the Lighthouse the following weekend. I do not think those who said they would come had any idea what they 
were being asked to do. I haven't mentioned before that it is a 20 kilometre walk with a number of steep climbs to access the lighthouse with the extraordinarily steep climb at the very end of the 20 kilometres. As we walked along the conference people were saying things along the lines of "I haven't been on a walk like this since I was 20." "It is very nice to get out of the City." This lasted for the first 5 or 6 kilometres then there was far less conversation. It was a miracle a couple of the walker survived without serious injury or a heart attack. And the reason for the weight of some packs became apparent. Adrian recovered with a nap. The next day we had all recovered and everyone look remarkably well.
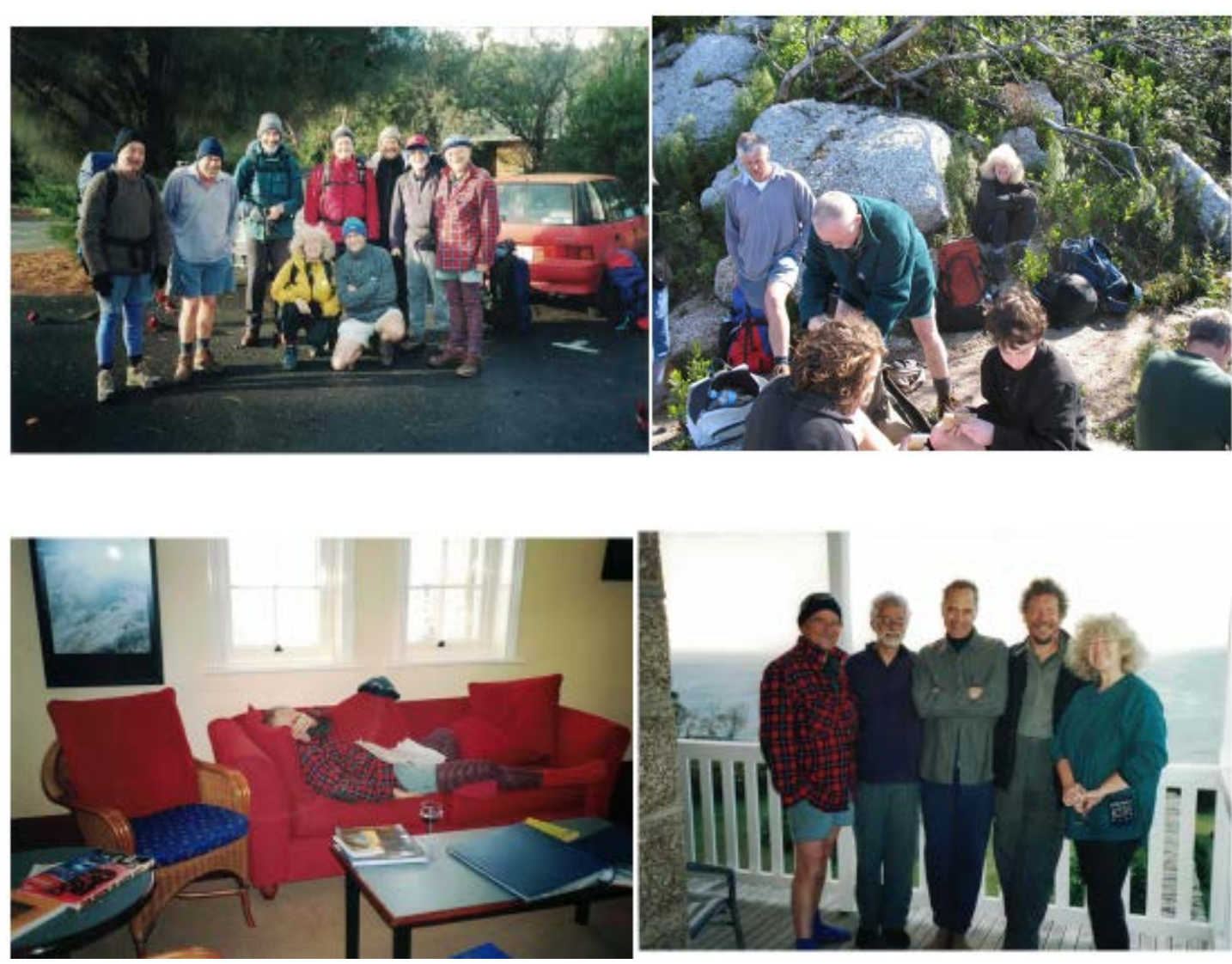
My last comment is about the hugs. I love Adrian and miss seeing him regularly. I love his hugs. My husband, however, is hug averse. I am known to wander past him when a male friend is hugging him and say quietly hands off your sides and on their back. So I thought you would like this final slide of Peter having a small hug around the shoulders from Adrian whilst having a photo taken. Keep hugging Adrian it is good for all of us.

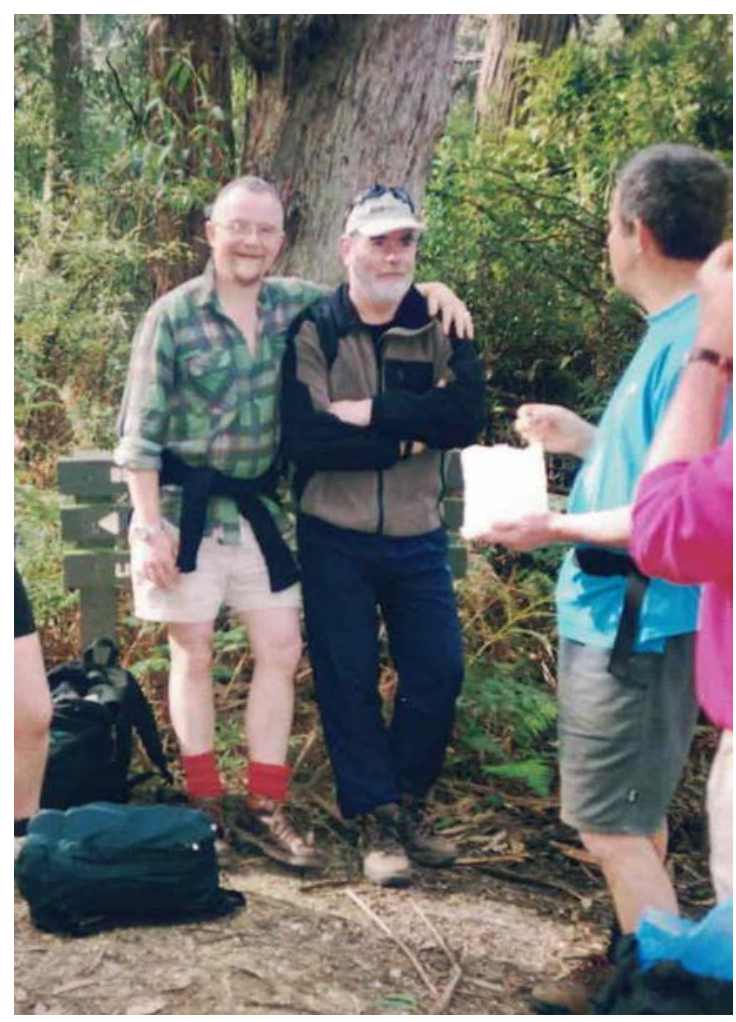

Adrian have a great time in the next part of your life and I am looking forward to the Lighthouse in 2019. 